\title{
PENGARUH KOMPENSASI DAN BUDAYA ORGANISASI TERHADAP KINERJA DENGAN MEDIASI KEPUASAN KERJA PERAWAT DI RUANG RAWAT INAP RSUD KARDINAH KOTA TEGAL
}

\author{
Nur Fitriani; Basukiyatno \\ RSUD Kardinah \\ Universitas Pancasakti Tegal
}

\begin{abstract}
The purpose of this study is to examine and analyze the effect of compensation and organizational culture on performance by mediating job satisfaction of nurses.

In this study, the population was all nurses in the Civil Hospital inpatient Kardinah. The sampling method using purposive sampling. Retrieval of data using questionnaires. Tests conducted by the research instrument validity and reliability, statistical test equipment being used is multiple regression analysis, $R 2$ test and t-test, to test the significance of regression coefficients generated.
\end{abstract}

The results showed that compensation is positive and significant effect on affective commitment, job satisfaction and commitment continuants, but had no effect on performance. Organizational culture of innovation and risk-taking has positive influence on affective commitment and performance. Results-oriented organizational culture has a positive effect on job satisfaction and performance. People-oriented organizational culture has a positive effect on job satisfaction. Affective commitment and commitment continuants positive effect on job satisfaction but had no effect on performance. Job satisfaction has a positive effect on performance. Affective commitment, job satisfaction and commitment continuants is purely capable of mediating variables to explain the effect of indirect compensation to performance. Affective commitment and job satisfaction are not able to explain the indirect effect of organizational culture of innovation and risk-taking on the performance of nurses in hospitals Kardinah Tegal City.

Keywords: compensation, organizational culture, , job satisfaction and performance of nurses

\section{A. PENDAhULUAN}

Kinerja (performance) merupakan perilaku organisasi yang secara langsung berhubungan dengan produksi barang atau penyampaian jasa.Kinerja seringkali dipikirkan sebagai pencapaian tugas, dimana istilah tugas sendiri berasal dari pemikiran aktifitas yang dibutuhkan oleh pekerja. Anwar Prabu (2000:67) berpendapat bahwa Kinerja (prestasi kerja) adalah hasil kerja secara kualitas dan kuantitas yang dicapai oleh seseorang pegawai dalam melaksanakan tugasnya sesuai dengan tanggung jawab yang diberikan kepadanya. Kinerja merupakan hasil kerja yang dilakukan oleh seorang pegawai dalam upaya pencapaian tujuan organisasi.

Hasibuan (2011:202) menyebutkan bahwa kepuasan kerja didefinisikan sebagai sikap emosional yang menyenangkan dan mencintai pekerjaannya. 
Sikap ini dicerminkan oleh moral kerja, kedisiplinan dan prestasi kerja. Kepuasan kerja dinikmati dalam pekerjaan, luar pekerjaan, dan kombinasi dalam dan luar pekerjaan. Lebih lanjut Hasibuan (2011:203) menyatakan bahwa kepuasan kerja dalam pekerjaan adalah kepuasan kerja yang dinikmati dalam pekerjaan dengan memperoleh pujian hasil kerja, penempatan, perlakuan, peralatan, dan suasana lingkungan kerja yang baik.

Gibson et.al. (1996:69) dalam Brahmasari (2008) dalam jurnalnya bahwa terdapat keterikatan antara penghargaan dan kinerja, dimana argumentasi berkenaan dengan kinerja yaitu: Satisfaction causes performance (kepuasan akan mengakibatkan kinerja), dan Rewards causes satisfaction and performance (imbalan/kompensasi akan mengakibatkan kinerja dan kepuasan). Kompensasi berperan dalam memberikan kepuasan kerja serta peningkatan kinerja pegawai, karena besarnya kompensasi yang diterima dapat meningkatkan kepuasan dan kinerja pegawai.

Berdasarkan hasil evaluasi SPM (Standar Pelayanan Minimal) rawat inap Tahun 2013, tingkat kepuasan pelanggan sebesar $45 \%$ menyatakan puas, 52\% cukup puas padahal standar minimal 90\%. Hal ini menunjukkan bahwa masih terdapat $3 \%$ pasien yang belum merasa puas terhadap pelayanan rumah sakit, dalam hal ini adalah perawat di ruang rawat inap. Pasien pulang paksa berdasarkan standar maksimal 5\%, akan tetapi capaian yang terjadi sebesar $6,30 \%$, hal ini menunjukkan bahwa masih banyak pasien yang kurang puas dengan kualitas pelayanan dari rumah sakit, sehingga memilih pulang paksa daripada melanjutkan perawatan di rumah sakit.

\section{B. TINJAUAN PUSTAKA}

Kompensasi menurut Hasibuan (2007:117) adalah semua pendapatan yang berbentuk uang, barang langsung maupun tidak langsung yang diterima karyawan sebagai imbalan atasjasa yang diberikan kepada perusahaan. Kompensasi merupakan istilah luas yang berkaitan dengan imbalan-imbalan finansial (financial reward) yang diterima oleh orang-orang melalui hubungan kepegawaian mereka dengan sebuah organisasi.

Menurut Luthans (1998:253), kompensasi dapat dibagi menjadi tiga komponen utama yaitu:

a) Kompensasi dasar, yaitu kompensasi yang jumlah dan waktu pembayaran tetap seperti gaji dan upah.

b) Kompensasi variabel, yaitu kompensasi yang jumlah dan waktu pembayarannya bervariasi atau tidak pasti seperti pembayaran insentif pada individu maupun kelompok, bonus, dan pembagian keuntungan.

c) Kompensasi tidak langsung, yang termasuk dalam kompensasi ini adalah jaminan sosial, asuransi, tunjangan kesehatan, dan pensiun.

Wibowo (2016: 77) budaya organisasi adalah merupakan filosofi dasar organisasi yang membuat keyakinan, norma-norma dan nilai-nilai bersama yang menjadi karakteristik inti tentang bagaimana cara melakukan sesuatu dalam organisasi. Budaya organisasi sangat diperlukan dan berperan penting untuk mencapai kinerja puncak organisasi.

Namun budaya organisasi harus selalu bergerak, berubah dan melakukan transformasi sesuai dengan kebutuhan organisasi dalam menanggapi perubahan lingkungan strategis. Mengubah budaya 
organisasi memberikan solusi untuk membantu organisasi bertahan dalam kondisi ekonomi yang selalu bergejolak. Budaya organisasi merupakan sarana untuk tetap relevan ditengah kompetisi global. Budaya organisasi mempengaruhi masa depan organisasi untuk berkembang ke tingkat yang lebih tinggi.

Robbins dalam Soedjono (2005) dalam jurnalnya juga mendefinisikan budaya organisasi (organizational culture) sebagai suatu sistem makna bersama yang dianut oleh anggotaanggota yang membedakan organisasi tersebut dengan organisasi yang lain. Lebih lanjut Robbins dalam Soedjono (2005) menyatakan bahwa: "a system of shared meaning held by member that distinguishes the organization from other organization. The system of shared meaning is, an closer examination, a set of key, charachteristics that the organization values".

Kepuasan kerja merupakan elemen penting dalam organisasi dalam pencapaian tujuan yang ditetapkan, karena kepuasan kerja dapat mempengaruhi perilaku kerja pegawai seperti rajin, malas, produktif, serta perilaku lain yang berhubungan dengan erat dalam pekerjaannya. Robbins dan Judge (2012: 99) mengemukakan bahwa kepuasan kerja (job satisfaction) adalah sebagai suatu perasaan positif tentang pekerjaan seseorang yang merupakan hasil dari evaluasi karakteristiknya. Seseorang dengan tingkat kepuasan kerja tinggi menunjukkan sikap positif terhadap pekerjaan itu, sebaliknya seseorang tidak puas dengan pekerjaannya menunjukkan sikap negatif terhadap pekerjaan itu.
Stephen P. Robbins (1997:26) mengatakan kinerja adalah ukuran performance yang meliputi efektivitas dan efisiensi. Efektif berkaitan dengan pencapaian sasaran, sedangkan efisien adalah ratio antara output yang efektif dengan input yang diperlukan untuk mencapai sasaran. Kinerja merupakan hasil yang dicapai dari perilaku anggota organisasi, Gibson (1997). Dengan demikian kinerja adalah hasil dari pekerjaan yang terkait dengan tujuan organisasi seperti kualitas, kuantitas dan efisiensi kerja.

Mangkunegara (2010:9) mendefinisikan kinerja adalah hasil kerja secara kualitas dan kuantitas yang dicapai oleh seseorang pegawai dalam melaksanakantugasnya sesuai dengan tanggung jawab yang diberikan kepadanya. Tsui, Pearce dan Tripoli (1997) dalam Winardi (2012), komponen untuk hasil kinerja yang dipilih untuk membedakan tugas-tugas. Mengingat bahwa sifat khusus karyawan sangat bervariasi dengan pekerjaan mereka, maka organisasi mengembangkan yang generik untuk satu pekerjaan. Enam item berfokus pada kualitas, kuantitas dan efisiensi karyawan dikembangkan untuk mengukur kinerja tugas dasar. Lebih lanjut Tsui et,al. (1997) menambahkan lima item yang diadaptasi dari Greenhaus, Parasuraman dan Wormley (1990) dalam Winardi(2012) untuk mengukur kinerja inti tugas, yaitu berfokus pada kemampuan keseluruhan individu, penilaian, akurasi, pengetahuan pekerjaan dan kreatifitas dalam melaksanakan tugas. 
Dari kerangka pemikiran teoritik diatas diperoleh model grafis sebagai berikut:

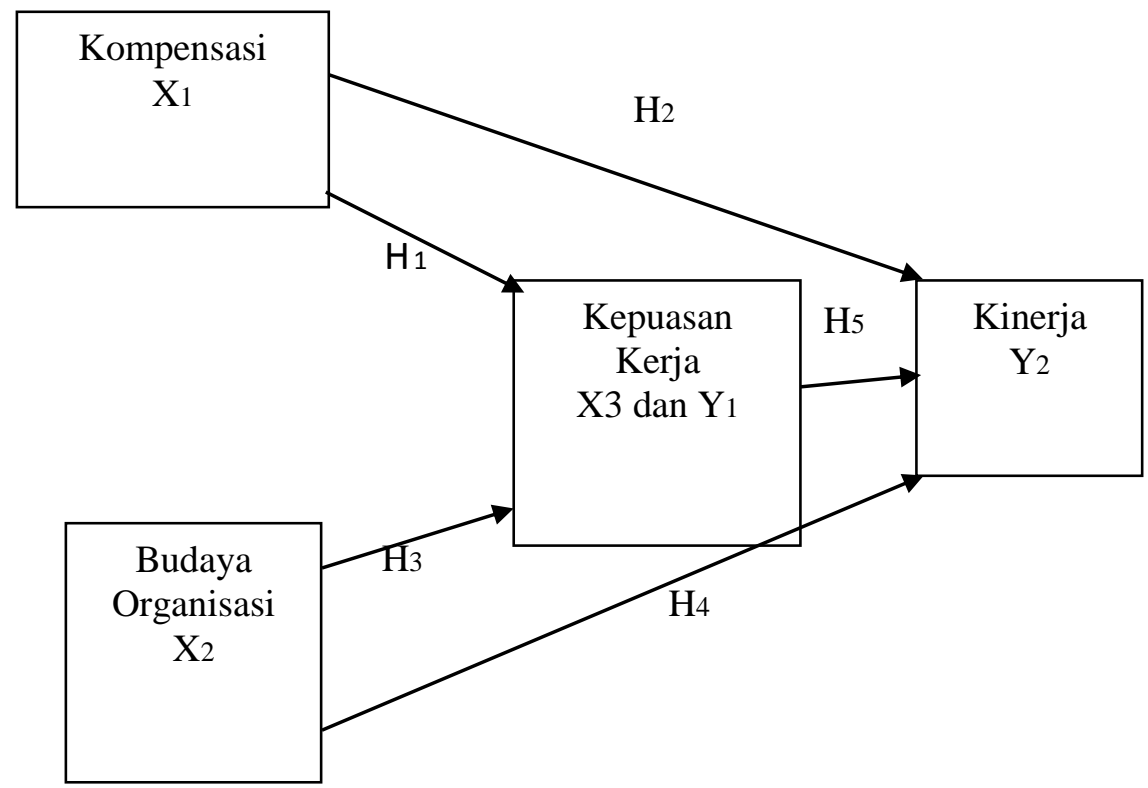

Gambar 2.1 Kerangka Berfikir

Herzberg (2009) menyatakan bahwa kompensasi sebagai faktor Hygiene dan bukan motivator, karena hal itu dapat menyebabkan kepuasan apabila jumlah uang yang diberikan sesuai dan ketidakpuasan apabila jumlah uang yang diberikan tidak sesuai. Menurut Ivancevich dan Matesson (1999) dalam Dwipasari (2008) ada yang menentukan apakah individu dipuaskan oleh kompensasi.

a) Kepuasan terhadap kompensasi merupakan suatu fungsi dari seberapa besar kompensasi diterima dan seberapa besar kompensasi dipersepsikan individu akan diterima.

b) Perasaan kepuasan individu akan dipengaruhi oleh perbandingan berbagai penghargaan instrinsik dan kompensasi yang ia terima dan diterima orang lain.

c) Kepuasan dipengaruhi oleh bagaimana seseorang dipuaskan oleh penghargaan instrinsik.

d) Kompensasi bagi setiap orang berbeda dan perbedaan tersebut terletak pada seberapa penting perbedaan kompensasi bagi mereka.

Beberapa kompensasi memberikan kepuasan pada karyawan karena mereka memperoleh kompensasi terbesar (dengan membandingkan kompensasi yang mereka terima dan yang diterima orang lain).

\section{METODE PENELITIAN}

Dalam penelitian ini menggunakan Penelitian kuantitatif. Menurut Sugiono (2012:7) metode penelitian kuantitatif dapat diartikan sebagai metode penelitian yang berlandaskan pada filsafat positivisme, digunakan untuk meneliti pada populasi atau sampel tertentu. Teknik pengambilan sampel pada umumnya dilakukan secara random, pengumpulan data menggunakan instrumen penelitian analisis data bersifat kuantitatif/statistik dengan tujuan untuk menguji hipotesis yang telah ditetapkan.

Penelitian kuantitatif merupakan studi yang diposisikan sebagai bebas 
nilai (value free). Dengan kata lain, penelitian kuantitatif sangat ketat menerapkan prinsip-prinsip objektivitas. Objektivitas itu diperoleh antara lain melalui penggunaan instrumen yang telãh diuji validitas dan reliabilitasnya. Peneliti yang melakukan studi kuantitatif mereduksi sedemikian rupa hal-hal yang dapat membuat bias, misalnya akibat masuknya persepsi dan nilai-nilai pribadi. Jika dalam penelaahan muncul adanya bias itu maka penelitian kuantitatif akan jauh dari kaidah-kaidah teknik ilmiah yang sesungguhnya (Sudarwan Danim, 2002: 35).

Pengujian ini terdiri atas uji Determinasi dan Uji Anova (Uji F).

Definisi mengenai Uji Determinasi dan Uji F (Prayitno dwi, 2008) adalah sebagai berikut:

a. Koefisien Determinasi $\left(\mathrm{R}^{2}\right)$

Adalah salah satu nilai statistik yang dapat digunakan untuk mengetahui prosentase besarnya perubahan variabel terikat (kinerja) yang disebabkan oleh Variabel bebas (kompensasi, Budaya Organisasi, dan kepuasan kerja). Koefisien determinasi menunjukkan kemampuan variabel bebas untuk menjelaskan variabel terikat.

b. Uji Anova (Uji F)

Adalah untuk mengetahui pengaruh variabel Independen secara simultan atau bersama-sama terhadap variabel dependen. Uji $F$ digunakan untuk mengetahui fit atau tidak terhadap model yang digunakan, dikatakan fit jika sig $\leq 0,05$.

\section{HASIL PENELITIAN}

Uji reabilitas adalah alat untuk mengukur suatu kuestioner yang merupakan indikator dari variable atau konstruk .pengukuran reabilitas pada penelitian ini dilakukan dengan cara one shot atau pengukuran satu kali, dimana reabilitas diukur dengan menggunakan uji statistic Cronbach yang dilakukan dengan SPSS . Di mana suatu variable dinilai realibel bila memiliki nilai Cronbach alpha> $0.70 \quad$ (Abass Ghozali,:2011: 48).

Dari tabel reabilitas terlihat bahwa keseluruhan pernyataan dalam penelitian adalah realibel dengan nilai Cronbach alpha > 0.70. yakni sebesar 0.921 (lihat tabel 4.3).

Tabel 4.3

Croncbach Alpha

Reliability Statistics

\begin{tabular}{|c|c|c|}
\hline Cronbach's Alpha & $\begin{array}{l}\text { Cronbach's Alpha } \\
\text { Based on } \\
\text { Standardized Items }\end{array}$ & $\mathrm{N}$ of Items \\
\hline .872 & .921 & 60 \\
\hline
\end{tabular}


Adapun nilai Croncbach alpha untuk masing masing Variabel adalah sebagai berikut :

a) Variabel Kompensasi

Tabel 4.4

Reliability Statistics

\begin{tabular}{|r|r|l|}
\hline srCronbach's Alpha & $\begin{array}{c}\text { Cronbach's Alpha } \\
\text { Based on } \\
\text { Standardized Items }\end{array}$ & N of Items \\
\hline .858 & .849 & 15 \\
\hline
\end{tabular}

Keseluruhan pernyataan dalam variabel kompensasi ini dapat dikatakan menjelaskan variabel karena memiliki nilai croncbach Alpha diatas 0.70 yakni 0.849 .

b) Variabel budaya Organisasi

Tabel 4.5

Reliability Statistics

\begin{tabular}{|r|r|rr|}
\hline & $\begin{array}{c}\text { Cronbach's Alpha } \\
\text { Based on } \\
\text { Cronbach's Alpha }\end{array}$ & Standardized Items & N of Items \\
\hline .851 & .856 & 15 \\
\hline
\end{tabular}

Keseluruhan pernyataan dalam variabel budaya organisasi ini dapat dikatakan menjelaskan variabel karena memiliki nilai croncbach Alpha diatas 0.70 yakni 0.856

c) Variabel Kepuasan Kerja

Tabel 4.6

Reliability Statistics

\begin{tabular}{|c|c|c|}
\hline Cronbach's Alpha & $\begin{array}{l}\text { Cronbach's Alpha } \\
\text { Based on } \\
\text { Standardized Items }\end{array}$ & $\mathrm{N}$ of Items \\
\hline .455 & .846 & 15 \\
\hline
\end{tabular}

Keseluruhan pernyataan dalam variabel kepuasan kerja ini dapat dikatan menjelaskan variabel karena memiliki nilai croncbach Alpha diatas 0.70 yakni 0.846

d) Variabel kinerja

Tabel 4.7

\section{Reliability Statistics}

\begin{tabular}{|r|r|r|}
\hline $\begin{array}{c}\text { Cronbach's } \\
\text { Alpha }\end{array}$ & $\begin{array}{c}\text { Cronbach's Alpha } \\
\text { Based on Standardized } \\
\text { Items }\end{array}$ & N of Items \\
\hline .836 & .863 & 15 \\
\hline
\end{tabular}

Keseluruhan pernyataan dalam variabel kepuasan kerja ini dapat dikatan menjelaskan variabel karena memiliki nilai croncbach Alpha diatas 0.70 yakni 0.863 
Uji validitas digunakan untuk mengukur validitas atau tidaknya suatu kuistioner. Suatu kuistioner dikatakan valid bilamana pertanyaan pada kuistioner mampu mengungkapkan sesuatu yang diukur oleh kuistioner tersebut.(imam Ghozali, 2011:52)
Dari tabel hasil SPSS terlihat semua variabel kompensasi, Budaya organisasi, kepuasan kerja dan kinerja memiliki signifikasi dibawah 0.05 yang berarti bahwa semua variabel adalah valid. Dan dimana Nilai Pearson Correlatiom diatas 0.05 .

Tabel 4.8

Correlations

\begin{tabular}{|ll|r|r|r|r|}
\hline & & \multicolumn{1}{|c|}{$\mathrm{Y}$} & \multicolumn{1}{c|}{$\mathrm{X} 1$} & \multicolumn{1}{c|}{$\mathrm{X} 2$} & \multicolumn{1}{c|}{$\mathrm{X} 3$} \\
\hline Pearson & $\mathrm{Y}$ & 1.000 & .239 & .506 & .544 \\
Correlation & $\mathrm{X} 1$ & .239 & 1.000 & .437 & .265 \\
& $\mathrm{X} 2$ & .506 & .437 & 1.000 & .259 \\
& $\mathrm{X} 3$ & .544 & .002 & .259 & 1.000 \\
\hline Sig. (1-tailed) $\mathrm{Y}$ & .000 & .004 & .000 & .000 \\
& $\mathrm{X} 1$ & .004 & .000 & .000 & .001 \\
& $\mathrm{X} 2$ & .000 & .000 & .000 & .002 \\
& $\mathrm{X} 3$ & .000 & .001 & .002 & .004 \\
\hline $\mathrm{N}$ & $\mathrm{Y}$ & 120 & 120 & 120 & 120 \\
& $\mathrm{X} 1$ & 120 & 120 & 120 & 120 \\
& $\mathrm{X} 2$ & 120 & 120 & 120 & 120 \\
$\mathrm{X} 3$ & 120 & 120 & 120 & 120 \\
\hline
\end{tabular}

Uji autokorelasi bertujuan untuk menguji apakah dalam model regresi linier ada korelasi antara kesalahan pengganggu pada periode $\mathrm{t}$ dengan kesalahan pengganggu pada periode t1 (sebelumnya). Jika terjadi korelasi maka dinamakan ada problem autokorelasi.

Autokorelasi muncul karena observasi yang berurutan sepanjang waktu berkaitan sama lainnya. Masalah ini timbul karena residual (kesalahan pengganggu) tidak bebas dari satu observasi ke observasi lannya.tentu saja model regresi yang baik adalah regresi yang bebas dari autokorelasi.
Deteksi autokorelasi bila: (Purbayu Budi Santosa,2005 : 240)

1. Angka Durbin Watson dibawah $-2=$ ada autokorelasi positif.

2. Angka Durbin Watson antara -2 sampai $+2=$ tidak ada autokorelasi

3. Angka Durbin Watson diatas $+2=$ ada autokorelasi negatif.

Untuk mendapatkan hasil perhitungan yang akurat dan melakukan proses perhitungan dengan cepat, semua langkah-langkah analisis data diatas dihitung dengan bantuan komputer menggunakan program aplikasi SPSS 16.0 . 
Tabel 4.10

Model Summary ${ }^{b}$

\begin{tabular}{|c|c|c|c|c|c|c|c|c|c|c|}
\hline \multirow[b]{2}{*}{ Model } & & \multirow[b]{2}{*}{$\begin{array}{c}\mathrm{R} \\
\text { Square }\end{array}$} & \multirow[b]{2}{*}{$\begin{array}{l}\text { Adju } \\
\text { sted } \\
\text { R } \\
\text { Squa } \\
\text { re }\end{array}$} & \multirow[b]{2}{*}{$\begin{array}{l}\text { Std. } \\
\text { Error of } \\
\text { the } \\
\text { Estimat } \\
\quad \mathrm{e}\end{array}$} & \multicolumn{5}{|c|}{ Change Statistics } & \multirow[b]{2}{*}{$\begin{array}{l}\text { Durbin- } \\
\text { Watson }\end{array}$} \\
\hline & & & & & $\begin{array}{c}\text { R } \\
\text { Squar } \\
\text { e } \\
\text { Chang } \\
\text { e }\end{array}$ & $\begin{array}{c}\text { F } \\
\text { Chan } \\
\text { ge }\end{array}$ & df1 & df 2 & $\left|\begin{array}{c}\text { Sig. F } \\
\text { Chang } \\
\mathrm{e}\end{array}\right|$ & \\
\hline 1 & $.667^{\mathrm{a}}$ & .445 & .431 & 3.970 & .445 & $\begin{array}{r}30.9 \\
96\end{array}$ & 3 & 116 & .000 & 1.892 \\
\hline
\end{tabular}

a. Predictors: (Constant), kepuasan,

kompensasi, budorgan

b. Dependent Variable: kinerja

Analisis regresi adalah analisis yang mengukur pengaruh variable bebas terhadap variable terkait. Analisis regresi linier berganda dalam penelitian ini merupakan analisis data yang digunakan untuk menguji hipotesis yaitu mengetahui apakah terdapat pengaruh yang signifikan antara variabel bebas antara kompensasi, budaya organisasi terhadap kinerja dengan kepuasan kerja sebagai intervening.

Tabel 4.11

Tabel Ouput SPSS Regressi

\begin{tabular}{|c|c|c|c|c|c|c|}
\hline & & \multicolumn{2}{|c|}{$\begin{array}{l}\text { Unstandardized } \\
\text { Coefficients }\end{array}$} & $\begin{array}{c}\text { Standardized } \\
\text { Coefficients }\end{array}$ & \multirow[b]{2}{*}{$\mathrm{t}$} & \multirow[b]{2}{*}{ Sig. } \\
\hline \multicolumn{2}{|c|}{ Model } & B & Std. Error & Beta & & \\
\hline 1 & (Constant) & 48.862 & 4.909 & & 9.954 & .000 \\
\hline & kompensasi & .086 & .062 & .137 & 3.393 & .016 \\
\hline & budorgan & .287 & .089 & .319 & 3.236 & .002 \\
\hline
\end{tabular}

a. Dependent Variable: kepuasan

Berdasarkan output data SPSS 16.0 (lihat table diatas) maka didapatkan persamaan akhir sebagai berikut:

Jalur I . Y kepuasan kerja $=\mathbf{4 8 . 8 6 2}+$ 0.86 kompensasi +0.287 budaya organisasi $+e$

Dari persamaan diatas dapat dijelaskan sebagai berikut:

a. bahwa nilai konstanta sebesar 48.862 menyatakan jika kompensasi dan budaya organisasi stagnan maka, maka kepuasan kerja kenaikan sebesar 1 persen.

b. Koefisien regresi kompensasi sebesar 0,86 menyatakan bahwa setiap kenaikan 1 persen kompensasi , maka akan mengurangi kepuasan keja sebesar 0,86persen.

c. Koefisien regresi budaya oraganisasi sebesar 0.287 menyatakan bahwa setiap peningkatan 1 persen budaya organisasi, maka kepuasan akan naik sebesar 0.287 persen. 
Jalur II

Tabel 4.12

Tabel Ouput SPSS Regressi

\begin{tabular}{|c|c|c|c|c|c|c|}
\hline \multirow{2}{*}{\multicolumn{2}{|c|}{ Model }} & \multicolumn{2}{|c|}{$\begin{array}{c}\text { Unstandardized } \\
\text { Coefficients }\end{array}$} & \multirow{2}{*}{$\begin{array}{c}\begin{array}{c}\text { Standardized } \\
\text { Coefficients }\end{array} \\
\text { Beta }\end{array}$} & \multirow[b]{2}{*}{$\mathrm{t}$} & \multirow[b]{2}{*}{ Sig. } \\
\hline & & B & Std. Error & & & \\
\hline \multirow[t]{4}{*}{1} & (Constant) & 10.075 & 5.191 & & 1.941 & .055 \\
\hline & kompensasi & .052 & .048 & -.084 & 1.080 & .002 \\
\hline & Budorganss & .316 & .072 & .352 & 4.389 & .001 \\
\hline & kepuasan & .452 & .072 & .453 & 6.276 & .001 \\
\hline
\end{tabular}

a. Dependent Variable: kinerja

\section{Jalur II}

$Y$ kinerja $=10.075+0.52$ kompensasi +0.316 budaya organisasi +0.452 kepuasan kerja $+e$
Suatu pengujian untuk menentukan apakah jawaban teoritis yang terkandung dalam pernyataan hipotesis di dukung oleh fakta-fakta yang dikumpulkan dan dianalisis dalam proses pengolahan data.

Tabel 4.15

Tabel Ouput SPSS Regressi

\begin{tabular}{|c|c|c|c|c|c|}
\hline \multirow{2}{*}{ Model } & \multicolumn{2}{|c|}{$\begin{array}{l}\text { Unstandardized } \\
\text { Coefficients }\end{array}$} & \multirow{2}{*}{\begin{tabular}{|c}
$\begin{array}{c}\text { Standardized } \\
\text { Coefficients }\end{array}$ \\
Beta \\
\end{tabular}} & \multirow[b]{2}{*}{$\mathrm{t}$} & \multirow[b]{2}{*}{ Sig. } \\
\hline & B & Std. Error & & & \\
\hline 1 (Constant) & 48.862 & 4.909 & & 9.954 & .000 \\
\hline kompensasi & .086 & .062 & .137 & 3.393 & .002 \\
\hline budorgan & .287 & .089 & .319 & 3.236 & .002 \\
\hline
\end{tabular}

a. Dependent Variable: kepuasan

Hasil Output SPSS Analisis Regresi BergandaCoefficients ${ }^{a}$

\begin{tabular}{|l|r|r|r|r|r|}
\hline \multirow{2}{*}{ Model } & \multicolumn{2}{|c|}{$\begin{array}{c}\text { Unstandardized } \\
\text { Coefficients }\end{array}$} & $\begin{array}{c}\text { Standardized } \\
\text { Coefficients }\end{array}$ & & \multirow{2}{*}{ Sig. } \\
\cline { 2 - 5 } & \multicolumn{1}{|c|}{$\mathrm{B}$} & Std. Error & \multicolumn{1}{c|}{ Beta } & \multicolumn{1}{c|}{$\mathrm{t}$} & \multicolumn{1}{c|}{ Seta } \\
\hline 1 (Constant) & 10.075 & 5.191 & & 1.941 & .055 \\
\multicolumn{1}{|c|}{ Kompensasi } & .052 & .048 & -.084 & 1.080 & .160 \\
Budorganisasi & .316 & .072 & .352 & 4.389 & .001 \\
Kepuasan & .452 & .072 & .453 & 6.276 & .001 \\
\hline
\end{tabular}




\begin{tabular}{|l|r|r|r|r|r|}
\hline \multirow{2}{*}{ Model } & \multicolumn{2}{|c|}{$\begin{array}{c}\text { Unstandardized } \\
\text { Coefficients }\end{array}$} & $\begin{array}{c}\text { Standardized } \\
\text { Coefficients }\end{array}$ & & \multirow{2}{*}{ Sig. } \\
\cline { 2 - 4 } & \multicolumn{1}{c|}{$\mathrm{B}$} & Std. Error & \multicolumn{1}{c|}{ Beta } & \multicolumn{1}{c|}{$\mathrm{t}$} & \multicolumn{1}{c|}{ Sig. } \\
\hline 1 (Constant) & 10.075 & 5.191 & & 1.941 & .055 \\
Kompensasi & .052 & .048 & -.084 & 1.080 & .160 \\
Budorganisasi & .316 & .072 & .352 & 4.389 & .001 \\
Kepuasan & .452 & .072 & .453 & 6.276 & .001 \\
\hline
\end{tabular}

a. DependentVariable:kinerja

\section{E. SIMPULAN DAN SARAN}

Setelah dilakukan pengolahan data dan analisis, selanjutnya akan ditarik kesimpulan yang didasarkan dari hasil pengujian pengaruh variabel bebas terhadap variabel terikat. Secara lengkap, kesimpulan yang dapat diuraikan adalah sebagai berikut:

1. Kompensasi memiliki pengaruh terhadap kepuasan kerja perawat di ruang rawat inap RSUD Kardinah Kota Tegal, artinya peningkatan kompensasi akan memberikan peningkatan kepuasan kerja perawat di ruang rawat inap RSUD Kardinah Kota Tegal.

2. Kompensasi tidak berpengaruh terhadap kinerja perawat di ruang rawat inap RSUD Kardinah Kota Tegal. Artinya kompensasi yang diberikan oleh organisasi belum dapat memberikan pengaruh pada peningkatan kinerja perawat di ruang rawat inap RSUD Kardinah Kota Tegal.

3. Budaya organisasi memiliki pengaruh terhadap kepuasan kerja perawat di ruang rawat inap RSUD Kardinah Kota Tegal, artinya bahwa peningkatan budaya organisasi akan diikuti oleh peningkatan kepuasan kerja perawat di ruang rawat inap RSUD Kardinah Kota Tegal.
4. Budaya organisasi memiliki pengaruh terhadap kinerja perawat di ruang rawat inap RSUD Kardinah Kota Tegal, artinya bahwa peningkatan budaya organisasi akan diikuti oleh peningkatan kinerja perawat di ruang rawat inap RSUD Kardinah Kota Tegal.

5. Kepuasan kerja memiliki pengaruh terhadap kinerja perawat di ruang rawat inap RSUD Kardinah Kota Tegal, artinya bahwa peningkatan kepuasan kerja akan diikuti oleh adanya peningkatan kinerja perawat di ruang rawat inap RSUD Kardinah Kota Tegal.

\section{Keterbatasan Penelitian}

Keterbatasan dalam penelitian ini adalah:

1. Sampel dalam penelitian ini adalah perawat PNS di ruang rawat inap RSUD Kardinah Kota Tegal dengan metode sensus, sehingga diperlukan kehati-hatian dalam melakukan generalisasi terhadap temuan penelitian ini.

2. Variabel yang digunakan dalam penelitian ini masih terbatas pada kompensasi dan budaya organisasi terhadap kinerja dengan mediasi dan kepuasan kerja perawat, sehingga penelitian ini masih perlu adanya kajian-kajian secara teoritik dan 
empirik secara lebih mendalam mengenai faktor-faktor tersebut, mengingat hasil penelitian ini belum sepenuhnya mengungkap gejala atau fenomena yang terjadi di obyek yang diteliti.

\section{Rekomendasi}

Berdasarkan kesimpulan dalam penelitian ini, saran yang dapat diberikan adalah sebagai berikut:

1. RSUD kardinah diharapkan dalam sistem penggajiannya dapat menfokuskan kepada kompensasi yang diberikan kepada perawat misal dengan bonus, promosi, penghargaan dan lain lainnya agar dapat meningkatkan kepuasan kerja perawat rawat inap di rumah sakit. Konsentrasi meningkatkan kepuasan kerja perawat RSUD Kardinah kotaTegal dapat meningkatkan juga kinerja perawat tersebut. Ini akan berdampak positif terhadap kemajuan
RSUD Kardinah dikota Tegal. Sedangkan untuk peningkatan kinerjanya karena peningkatan kompensasi tidak memberikan pengaruh maka diharapkan kedepan agar RSUD Kardinah Kota Tegal perlu memperhatikan kembali sistem pemberian kompensasi yang ada, dalam rangka peningkatan prestasi kerja perawat di ruang rawat inap.

2. RSUD Kardinah kota Tegal kedepan lebih meningkatkan budaya organisasi misal dengan mendorong inovasi perawat, adanya pelatihan perawat dalam rangka peningkatan prestasi, memberikan penghargaan kepada perawat yang berprestasi dan hubungan yang lebih baik antara pimpinan dan karyawan serta sesame karyawan. Semua itu dapat meningkatkan kepuasan dan sekaligus kinerja dari perawat rawat inap di rumah sakit tersebut.

\section{DAFTAR PUSTAKA}

Abdullah dan Herlin Arisanti, 2010. Pengaruh Budaya Organisasi, Komitmen Organisasi dan Akuntabilitas Publik terhadap Kinerja Organisasi. Jurnal Ekonomi dan Bisnis, Vol. 9, No. 2, Agustus 2010: 118-134.

Ardani, L. 2006. Analisis Perbandingan Pengaruh Langsung Dan Tak Langsung Faktor Budaya Organisasi Dan Komitmen Terhadap Kinerja Karyawan Pada UPTD Parkir Kota Surabaya. EKUITAS. Vol.13 No. 2 Juni 2009:238258.

Arisanti, KI. 2009. Pengaruh Budaya Organisasi dan Komitmen Organisasional Terhadap Kepuasan Kerja Karyawan. Proceeding PESAT (Psikologi, Ekonomi, Sastra, Arsitektur, \& Sipil), Universitas Gunadarma. Vol.3 Oktober 2009.

Bagyo, Y. 2009. Komitmen Organisasi Merupakan Variabel Mediasi Hubungan Kompensasi Finansial dan Non Finansial terhadap Kinerja Karyawan Studi pada Karyawan PT Bank UOB Buana Capem Tabanan-Bali. Jurnal Aplikasi Manajemen. Vol. 7 No. 4, November 2009.

Baron, R. M., \&Kenny, D. A. (1986). The moderator-mediator variable distinction in social psychological research: Conceptual, strategic, and statistical considerations. Journal of personality and social psychology, 51(6), 117.

Brahmasari, I.A. dan A. Suprayetno. 2008. Pengaruh Motivasi Kerja, Kepemimpinan dan Budaya Organisasi Terhadap Kepuasan Kerja Karyawan serta Dampaknya pada Pei Hai Internasional Wiratama Indonesia. Jurnal Manajemen dan Kewirausahaan. Vol. 10, No. 2:124-135. 
Buraidah. 2011. Pengaruh Kompensasi dan Motivasi Terhadap Komitmen Organisasi di Organisasi Pendidikan Islam X. Pasca Sarjana Psikologi, Universitas Gunadarma.

Dwipasari, L. 2008. Kompensasi dan Kedisiplinan Sebagai Faktor Yang Berpengaruh Terhadap Kinerja dan Kepuasan Kerja Karyawan Bank. Jurnal Keuangan dan Perbankan, Universitas Merdeka Malang. Vol. 12 No. 3 September 2008, Hal. 494-503.

Fathonah, S. dan U. Ida. 2012. Pengaruh Kompensasi, Pengembangan Karir, Lingkungan Kerja dan Komitmen Organisasi Terhadap Kepuasan Kerja Pegawai Sekretariat Daerah Kabupaten Karanganyar Dengan Keyakinan Diri (Self Efficacy) sebagai Variabel Pemoderasi. Jurnal Publikasi STIEAUB, Surakarta.

Fatmawati, Mahdani, dan I. Sofyan. 2012. Pengaruh Budaya Organisasi dan Rotasi Pekerjaan Terhadap Motivasi Kerja serta Implikasinya pada Kinerja Pegawai IAIN Ar-Raniry Banda Aceh. Jurnal Ilmu Manajemen, Pascasarjana Universitas Syiah Kuala, Vol. 1, Tahun I, No.1, Agustus 2012.

Ferdinand, Augusty. 2002. Structural Equation Modelling Dalam Penelitian Manajemen. Semarang: Badan Penerbit Universitas Diponegoro.

Ghozali, I. 2011. Aplikasi Analisis Multivariate dengan Program IBM SPSS 19. Badan Penerbit Universitas Diponegoro. Semarang.

Gibson, J.L., J.M. Invancevich, dan J.H.Donnelly. 1997. Organization. 9 Ed. Irwin Inc.

Gibson, J.L., J.M. Invancevich, J.H.Donnelly dan R. Konopaske. 2006. Organization: Behavior, Structure, Processes. 12 Ed. New York: McGrawHill/Irwin Inc.

Hair, J.F. JR., W. C. Black, B.J. Babin, R. E. Anderson, dan R.L. Tatham. 2006. Multivariate Data Analysis. Sixth Edition, Uper Sadle River, New Jeresey, Prentice Hall.

Hair, J.F. JR., W. C. Black, B.J. Babin, R. E. Anderson, dan R.L. Tatham. 2009. Multivariate Data Analysis. Seventh Edition, Uper Sadle River, New Jeresey, Prentice Hall.

Handoko, T.H. 1994. Manajemen Sumber Daya Manusia dan Manajemen Personalia. Edisi 2. Yogyakarta : Penerbit BPFE.

Handoko, T.H. 2000. Manajemen Personalia dan Sumber Daya Manusia. Yogyakarta : Penerbit BPFE.

Hasibuan, M.S.P. 2006. Manajemen Sumber Daya Manusia. Jakarta.: Binarupa Aksara.

Hasibuan, M.S.P. 2007. Manajemen Sumber Daya Manusia. Jakarta: Penerbit Bumi Aksara.

Hasibuan, M.S.P. 2009. Manajemen Sumber Daya Manusia. Edisi Revisi. Jakarta: Penerbit Bumi Aksara.

Handoko, T.H. 2011. Manajemen. Edisi 2. Yogyakarta : Penerbit BPFE.

Igalens, JR. 1999. A Study of the Relationship between Compensation Package, Work Motivation and Job Satisfaction. Journal of Organizational Behavior. No.20 pp 1003-1025.

Indriyani, E. dan Wisnu Haryanto P.C. 2012. Pengaruh Budaya Organisasi dan Kepuasan Kerja Terhadap Kinerja Karyawan dengan Komitmen Organisasi sebagai Variabel Intervening pada Workshop SMK Katolik Santo Mikael Surakarta. Jurnal Publikasi STIE-AUB, Surakarta. 
Kartiningsih. 2007. Analisa Pengaruh Budaya Organisasi dan Keterlibatan Kerja Terhadap Komitmen Organisasi Dalam Meningkatkan Kinerja Karyawan. Tesis. Universitas Diponegoro.

Kasiram 2008. Metodologi Penelitian Kualitatif dan Kuantitatif. Malang UIN. Malang Pers

Katz, E. \& Lazarsfeld, P.F. (1955) 'Personal influence: The part played by people in the flow of mass communications ${ }^{6}$, The Free Press, New York

Koesmono, H.T. 2005. Pengaruh Budaya Organisasi Terhadap Motivasi Dan Kepuasan Kerja Serta Kinerja Karyawan Pada sub SektorIndustri Pengolahan Kayu Skala Menengah di Jawa Timur. Jurnal Manajemen \& Kewirausahaan. Vol. 7, No.2: 171-188.

Kreitner, R. dan A. Kinicki. 2005. Organizational Behavior (Terjemahan). Buku I dan II, Edisi Kelima, Salemba Empat Jakarta.

Lewa, Eka Idham Iip K. dan Subowo. 2005. Pengaruh Kepemimpinan, Lingkungan Kerja Fisik dan Kompensasi terhadap Kinerja Karyawan di PT. Pertamina (Persero) Daerah Operasi Hulu Jawa Bagian Barat, Cirebon. Sinergi, Kajian Bisnis dan Manajemen, Edisi Khusus on Human Resources, Hal. 129-140.

Luthans, F. 1995. Organizational Behavior. Seventh Ed. Singapore. The McGrawHill. International Edition.

Luthans, F. 1997. Organizational Behavior. 3th Ed. New York. The Mc Graw Hill Co. Inc.

Luthans, F. 1998. Organizational Behavior. 8 th Ed. New York. The Mc Graw Hill Co. Inc.

Luthans, F. 2006. Perilaku Organisasi. Edisi 10, Jilid 1 dan 2, Terjemahan. Vivin Andhika Yuwono, Shekar Purwanti, Th. Arie P. Dan Winong Rosari, Yogyakarta: Penerbit Andi.

Manaroinsong, J. 2011. Pengaruh Faktor Kompetensi Individu dan Manajemen Kompensasi terhadap Kepuasan Kerja dan Kinerja Keuangan Daerah di Provinsi Sulawesi Utara. Jurnal Aplikasi Manajemen. Vol. 9, No. 3, Mei 2011:1090-1099.

Mangkunegara, A.P. 2005. Manajemen Sumber Daya Manusia Perusahaan. Bandung: Remaja Rosda Karya.

Mangkunegara, A.A. AP. 2010. Evaluasi Kinerja Sumber Daya Manusia. Bandung: Refika Aditama.

Meyer, JP. dan Allen, NJ. 1997. Commitment in the Workplace: Theory, research, California: SAGE Publication, Inc.

Moeljono, DS. 2003. Budaya Korporat dan Keunggulan Korporasi. PT. Elex Media Komputindo, Jakarta.

Mowday, R.T., R.M. Steers dan L. Porter. 1979. The Measurement of Organizational Commitment. Journal of Vacational Behavior. Vol.14: 224247.

Mowday, R.T., R.M. Steers dan L. Porter. 1982. Employee-organization. Hnkages In P. Warr (Ed.), Organization and Occupational psychology. New York: Academic Press, pp. 219-229.

Ndraha, T. 2007. Manajemen Sumber Daya Manusia. Edisi Kesatu, Cetakan Pertama, Badan Penerbit STIE-Yogyakarta. 
Prayitno, Dwi, 2008 Mandiri Belajar Statistical Produck dan service solusion. PT. Buku Kita Jakarta

Retnaningsih, W. 2011. Pengaruh Budaya Organisasi dan Kepuasan Kerja Terhadap Komitmen Organisasional di P.T. Inti Karya Persada Teknik Bogor.

Riyadi, S. 2011. Pengaruh Kompensasi Finansial, Gaya Kepemimpinan, dan Motivasi Kerja Terhadap Kinerja Karyawan pada Perusahaan Manufaktur di Jawa Timur. Jurnal Manajemen dan Kewirausahaan. Vol.13, No. 1, Maret 2011:40-45.

Robbins, S.P. 1998. Organization Behaviour. Singapore : Pretice-Hall International.

Robbins, S. P. 2001. Perilaku Organisasi: Konsep, Kontroversi dan Aplikasi. Jilid 1. Edisi Bahasa Indonesia, Pearson Asia Education, Pte., Ltd. Jakarta: Penerbit PT. Prenhallindo.

Robbins, S. P. 2003. Perilaku Organisasi. Jakarta: Penerbit PT. Indeks Kelompok Gramedia.

Robbins, S. P. dan T.A. Judge. 2008. Perilaku Organisasi. Edisi 12, Jilid 1 dan 2, Terjemahan. Jakarta: Penerbit Salemba Empat.

Robbins, S. P. dan T.A. Judge. 2012. Perilaku Organisasi. Edisi dua belas Buku dua, Terjemahan. Jakarta: Penerbit Salemba Empat.

Samsudin, S. 2005. Manajemen Sumber Daya Manusia. Bandung: Penerbit Pustaka Jaya.

Sari, E. 2009. Pengaruh Kompensasi dan Iklim Organisasi terhadap Kepuasan Kerja. Jurnal Ilmu Administrasi dan Organisasi. Vol. 16, No. 1, Jan-Apr 2009: 18-24.

Schein, E.H. 1997. Organizational Culture and Leadership. San Fransisco: Joersey Bass Publisher.

Schultz, D.P. dan Schultz, Sydney Ellen. 1990. Psychology and Industry Today : An introduction to Industrial and Organizational psychology. $5^{\text {th }}$ Ed. Maxwell Macmillan International Edition, USA.

Simamora, H. 1995. Manajemen Sumber Daya Manusia. Edisi kesatu, Cetakan pertama, Yogyakarta: Penerbitan STIE YKPN.

Simamora, H. 2006. Manajemen Sumber Daya Manusia. Edisi ketiga, Cetakan kedua, Yogyakarta: Penerbitan STIE YKPN.

Simmons, E.S. 2005. Predictors of Organizational Commitment Among Staff in Assited Living. The Gerontologist. Vol.45, 196-205.

Soedjono. 2005. Pengaruh Budaya Organisasi Terhadap Kinerja Organisasi dan Kepuasan Kerja Karyawan pada Terminal Penumpang Umum di Surabaya. Jurnal Manajemen \& Kewirausahaan. Vol. 7, No. 1, Maret 2005: 22-47.

Spector, PE. et. al. 2000. Industrial and Organizational Psychology: Research and Practise. Inc.USA.

Sugiyono. 2010. Metode Penelitian Bisnis. Bandung: Penerbit Alfabeta.

Sugiyono.(2007).Metode Penelitian pedidikan pendekatan kuantitatif, kualitatif, dan R\&D.Bandung: ALFABETA

Suharto \& B. Cahyono. 2005. Pengaruh Budaya Organisasi, Kepemimpinan dan Motivasi Kerja Terhadap Kinerja Sumber Daya Manusia di Sekretariat DPRD Propinsi Jawa Tengah. JRBI Vol.1, No. 1, Januari 2005: 13-30. 
Tobing, DS. K.L. 2009. Pengaruh Komitmen Organisasional dan Kepuasan Kerja Terhadap Kinerja Karyawan PT. Perkebunan Nusantara III di Sumatera Utara. Jurnal Manajemen dan Kewirausahaan. Vol. 11, No. 1, Maret 2009: 31-37.

Triyono, AF. 2011. Pengaruh Budaya Organisasi, Komitmen Organisasi, Kompensasi dan Iklim Organisasi Terhadap Kinerja Karyawan PT. Bank Rakyat Indonesia (Persero) Tbk. Kantor Cabang Klaten. Jurnal Publikasi STIE AUB, Surakarta.

Tsui, A. S., J. L. Pearce dan A. M. Tripoli. 1997. Alternative Approaches to The Employe- Organization Relationship: Does Investment in Employees Pay Off?. Akademy of Management Journal, Vol.40, No.5: 1089-1121.

Umar, H. 2005. Metode Penelitian Aplikasi Dalam Pemasaran. PT. Gramedia Utama, Jakarta.

Umiker, A. 1999. Management Accounting. International Edition. New Jersey. Englewood Cliffs. Prentice-Hall International, Inc.

Werther, W.B. adn Davis., Jr. Keith.1996. Human Resuorces And Personel Management. $5^{\text {th }}$ Ed. Mc Graw-Hill, Inc. United States of America.

Wikipedia Indonesia. 16 November 2012. Kompensasi. http://id.wikipedia.org/wiki/Kompensasi (finansial)

Winardi. 2011. Pengaruh Budaya Organisasi dan Motivasi Terhadap Kinerja Karyawan Dengan Komitmen Organisasional Sebagai Variabel Intervening : Studi pada Karyawan Dinas Pengairan Provinsi Aceh. Program Magister Manajemen, Universitas Syiah Kuala.

Wibowo. 2006. Manajemen Perubahan. Cetakan Pertama, PT. Raja grafindo Persada, Jakarta.

Wibowo. 2011. Budaya Organisasi. Cetakan Kedua, PT. Raja grafindo Persada, Jakarta.

Wibowo. 2016. Budaya Organisasi. Edisi kedua Cetakan Keempat, PT. Rajawali pers, Jakarta.

Zagladi, A.L. 2005. Pengaruh kelelahan emosional terhadap kepuasan kerja dalam pencapaian komitmen Organisasional. Jurnal Delegasi. No.1 April 2005:124

Yanidrawati, K. dkk. 2011. Hubungan Kepuasan Kerja dengan Kinerja Perawat di Ruang Rawat Inap RSUD Kabupaten Bekasi. Fakultas Keperawatan Universitas Padjdajaran. 